\title{
Revision of fossil Metretopodidae (Insecta, Ephemeroptera) in Baltic amber - Part 4: Description of two new species of Siphloplecton Clemens, 1915, with notes on the new $S$. jaegeri species group and with key to fossil male adults of Siphloplecton
}

\author{
Roman J. Godunko ${ }^{1,2}$, Christian Neumann ${ }^{3}$, Arnold H. Staniczek ${ }^{4}$ \\ I Biology Centre of the Czech Academy of Sciences, Institute of Entomology, Branišovská 31, 37005 Ceské \\ Budějovice, Czech Republic 2 Department of Invertebrate Zoology and Hydrobiology, University of Eódź, \\ Banacha 12/16, 90237, Eódź, Poland 3 Museum für Naturkunde, Leibniz Institute for Evolution and Bio- \\ diversity Science, 10115, Berlin, Germany 4 Department of Entomology, Stuttgart State Museum of Natural \\ History, Rosenstein 1, 70191, Stuttgart, Germany
}

Corresponding author: Arnold H. Staniczek (arnold.staniczek@smns-bw.de)

Academic editor: L. Pereira-da-Conceicoa | Received7 October 2019 | Accepted 8 November 2019| Published 10 December 2019

http://zoobank.org/7B407C80-9E64-4F59-95C2-B3229CF78C6B

Citation: Godunko RJ, Neumann C, Staniczek AH (2019) Revision of fossil Metretopodidae (Insecta, Ephemeroptera) in Baltic amber - Part 4: Description of two new species of Siphloplecton Clemens, 1915, with notes on the new $S$. jaegeri species group and with key to fossil male adults of Siphloplecton. ZooKeys 898: 1-26. https://doi.org/10.3897/ zookeys.898.47118

\begin{abstract}
The Siphloplecton jaegeri species group is established here for three extinct species, namely for the earlier described Siphloplecton jaegeri Demoulin, 1968, and for two new species from Eocene Baltic amber, Siphloplecton landolti sp. nov. and Siphloplecton studemannae sp. nov. Based on the well-preserved specimens of these species, a diagnosis is provided for the newly established species group. Representatives of the $S$. jaegeri species group are characterized by the presence of large, medially contiguous eyes, stout pointed setae along the outer margin of the foretibia, three intercalaries in the cubital field of the forewing, and elongated penis lobes, which are apically triangular or rounded, medially contiguous, and with a Vshaped cleft apically. Further new specimens of the $S$. jaegeri species group are documented that cannot be attributed to species level due to their poor preservation. Finally, a key to male adults of fossil species of Siphloplecton is given.
\end{abstract}

\section{Keywords}

Fossil insects, mayflies, Siphlonuroidea, new species, species group, Eocene

Copyright Roman J. Godunko et al. This is an open access article distributed under the terms of the Creative Commons Attribution License (CC BY 4.0), which permits unrestricted use, distribution, and reproduction in any medium, provided the original author and source are credited. 


\section{Introduction}

Metretopodidae Traver, 1935 is a small, monophyletic mayfly family of Holarctic distribution, comprising 11 extant species in three genera (Berner 1978; Kluge 2004). While Metretopus Eaton, 1901 is distributed throughout the Holarctic, the extant distribution of Siphloplecton Clemens, 1915 is restricted to the Nearctic, and Metreplecton Kluge, 1996 is only found in the Palearctic. Recently, Staniczek and Godunko (2012, 2015, 2016) provided an overview of the taxonomic history of fossil Metretopodidae, which are only known from Eocene Baltic amber. They addressed the two fossil species of Siphloplecton Clemens, 1915 treated by Demoulin (1968): S. jaegeri Demoulin, 1968 was redescribed, whereas the lectotype of $S$. macrops (Pictet-Baraban \& Hagen, 1856) was considered to be lost (Staniczek and Godunko 2012). Additionally, S. barabani Staniczek \& Godunko, 2012; S. picteti Staniczek \& Godunko, 2012; S. hageni Staniczek \& Godunko, 2012; and S. demoulini Staniczek \& Godunko, 2012 were described from historical material (Staniczek and Godunko 2012). The hitherto described fossil material of Metretopus (Demoulin, 1970) was also revised (Staniczek and Godunko 2015), and M. dividus Staniczek \& Godunko, 2015 was described from new material. In a third part of the revision of fossil Metretopodidae, the rediscovery of the $S$. macrops lectotype was documented (Staniczek and Godunko 2016). Based on new material, complementary descriptions of S. picteti and $S$. barabani were given, and the picteti and demoulini species groups were established within Siphloplecton. Finally, two new species, S. sartorii Staniczek \& Godunko, 2016 and S. gattolliati Staniczek \& Godunko, 2016, were described from newly emerged material and attributed to these species groups, respectively (Staniczek and Godunko 2016).

In this fourth contribution to the knowledge of fossil Metretopodidae, we establish the jaegeri species group within Siphloplecton based on newly available material. Two recently discovered, well preserved male imagines from Baltic amber provide new data for a complementary description of the fossil species Siphloplecton jaegeri; two new species, S. landolti sp. nov. and S. studemannae sp. nov., are described and attributed to this species group; and finally, further two new specimens of the $S$. jaegeri group are documented that cannot be attributed to species level due to their poor conservation.

\section{Material and methods}

All specimens examined in this study are housed in the following collections (for details see under Material examined in the species descriptions):

CCHH collection of Christel and Hans Werner Hoffeins, Hamburg, Germany (later to be housed at Senckenberg Deutsches Entomologisches Institut, Müncheberg, Germany (SDEI));

MNB Museum für Naturkunde, Berlin, Germany;

MNHK Museum of Natural History, Institute of Systematics and Evolution of Animals, PAS, Kraków, Poland; 
MNHN Muséum national d'Histoire naturelle, Paris, France;

SMNS Staatliches Museum für Naturkunde Stuttgart, Germany.

Drawings were made with a camera lucida on an Olympus SZX7, a Leica S8 APO and a Leica M205 C stereo microscopes. Multiple photographs with different depth of field were taken through a Leica Z16 APO Macroscope using Leica Application Suite v. 3.1.8. Photo stacks were processed with Helicon Focus Pro 6.4.1 to obtain combined photographs with extended depth of field, and subsequently enhanced with Adobe Photoshop CS3.

\section{Systematic palaeontology}

\section{Order Ephemeroptera Hyatt \& Arms, 1890}

Family Metretopodidae Traver, 1935

Genus Siphloplecton Clemens, 1915

\section{Siphloplecton jaegeri species group}

Diagnosis. Male imago: (1) eyes large, medially contiguous; (2) outer margin of foretibia with several stout, pointed setae; (3) cubital field with three long intercalary veins: one long intercalary vein connected with $\mathrm{CuA}$ by one or several crossveins; one pair of intercalary veins situated close to $\mathrm{CuP}$ and at least connected with $\mathrm{CuA}$ (or additionally with $\mathrm{CuP}$ ) by a crossvein; (4) styliger plate angulate, mediocaudally only shallowly incised; incisions with relatively small pronounced triangular projections; with or without medial projection, if present, small and bluntly pointed apically; (5) forceps relatively long; basal segment conical, without apical hump on inner margin; (6) penis stem elongated; (7) penis significantly surmounting distal end of styliger plate, reaching $0.25-0.30 \times$ length of forceps segment 2 ; (8) penis lobes elongated, apically triangular or rounded, medially contiguous, with $V$-shaped cleft apically.

Species composition. Siphloplecton jaegeri Demoulin, 1968, Siphloplecton landolti sp. nov., Siphloplecton studemannae sp. nov., Siphloplecton sp. 5, Siphloplecton sp. 6.

\section{Siphloplecton jaegeri Demoulin, 1968}

Figures 1-4; Table 1

Siphloplecton jaegeri Demoulin, 1968 - Deutsche Entomologische Zeitschrift. 252, figs 18a, c (description, designation of holotype)

Siphloplecton jaegeri Demoulin, 1968 - Staniczek and Godunko 2012, Paleodiversity:

73 , figs 10a, b, 11a-c (redescription of holotype). For complete list of synonymies see Staniczek and Godunko (2012: 73). 

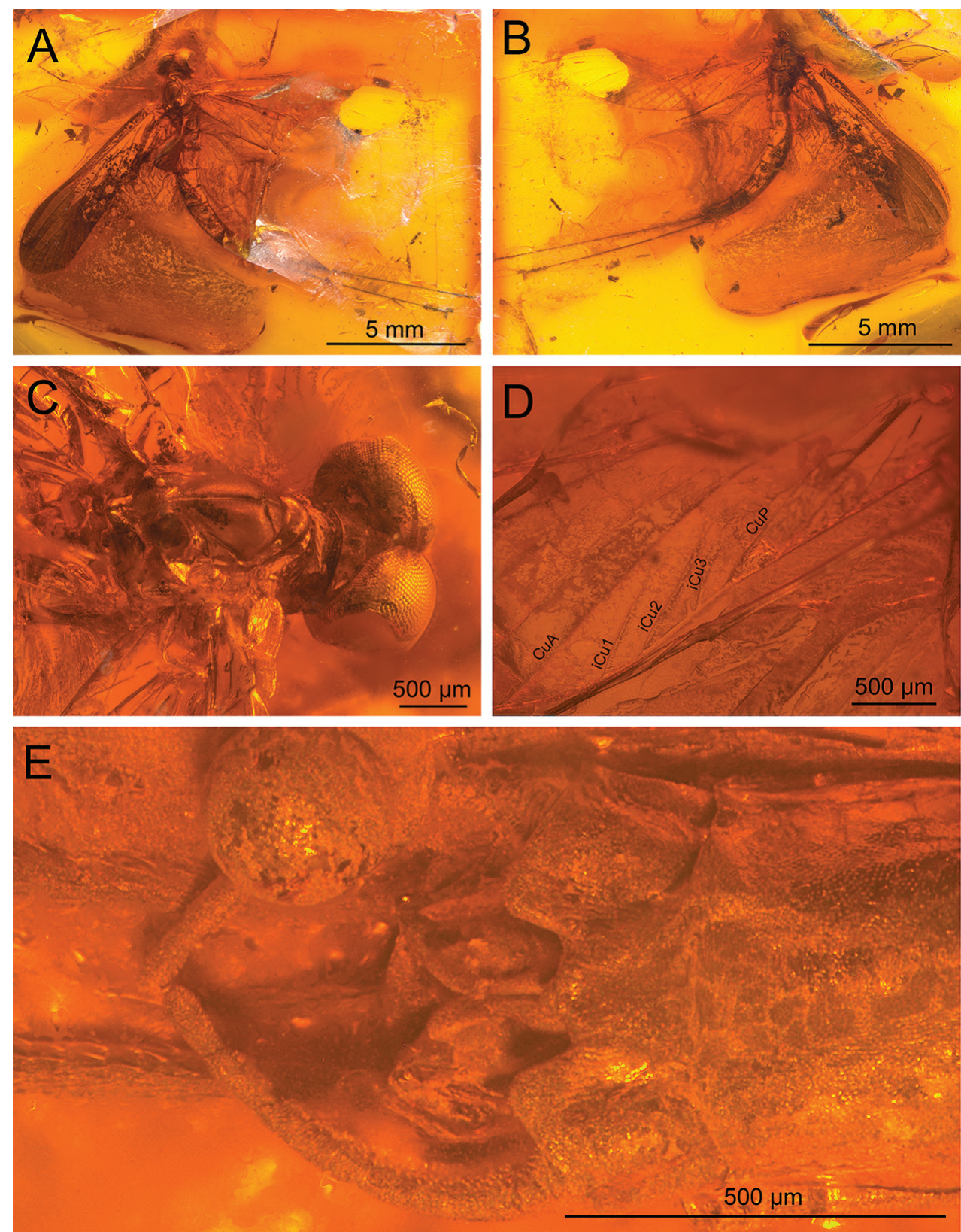

Figure I. Siphloplecton jaegeri Demoulin, 1968, MNB, MB.I 7370, male imago (photographs) A general dorsal view $\mathbf{B}$ general ventral view $\mathbf{C}$ head and thorax in dorsal view $\mathbf{D}$ right forewings (details of cubital field in ventral view) $\mathbf{E}$ genitalia in ventral view.

Material examined. Male imago in Baltic amber (Eocene), MNB, MB.I 7370, specimen labelled as: "6. Pseudoneuroptera III Ephemeridae"; "Museum für Naturkunde Berlin”; "Paläontologisches Museum”; "Slg.: Künow Inv. Nr.: Nr. 268-294 nur noch 


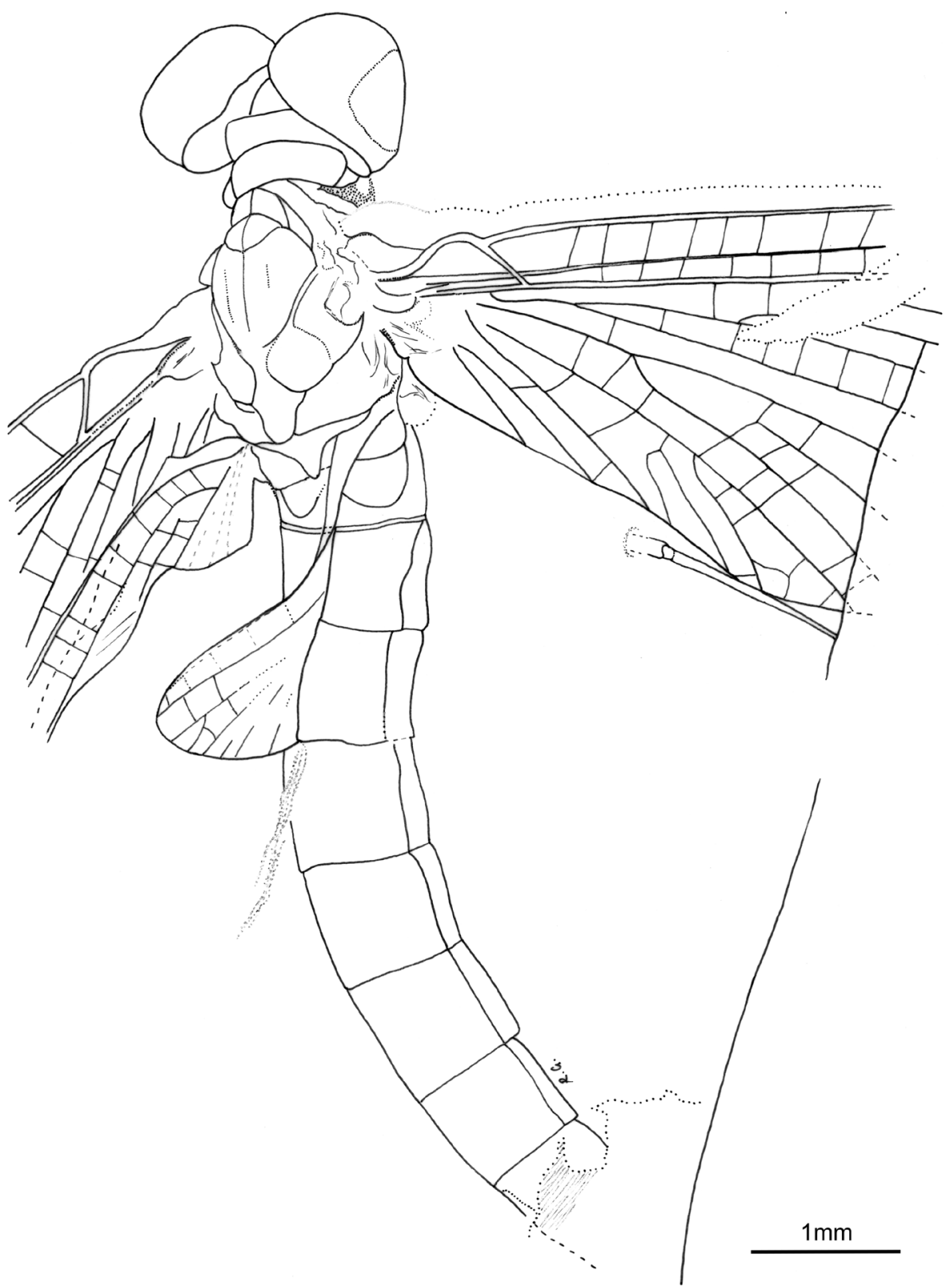

Figure 2. Siphloplecton jaegeri Demoulin, 1968, MNB, MB.I 7370, male imago (line drawing): general dorsal view.

9 Stück vorgefunden"; "Ephemeriden"; "Siphloplecton cf. jaegeri ô imago Nr.: 271" (Figs 1A-E, 2).

Well preserved specimen, visible in dorsoventral aspect. Wings completely preserved (Fig. 1A, B); posterior margin of left forewing and hind wings twisted. Ventral 

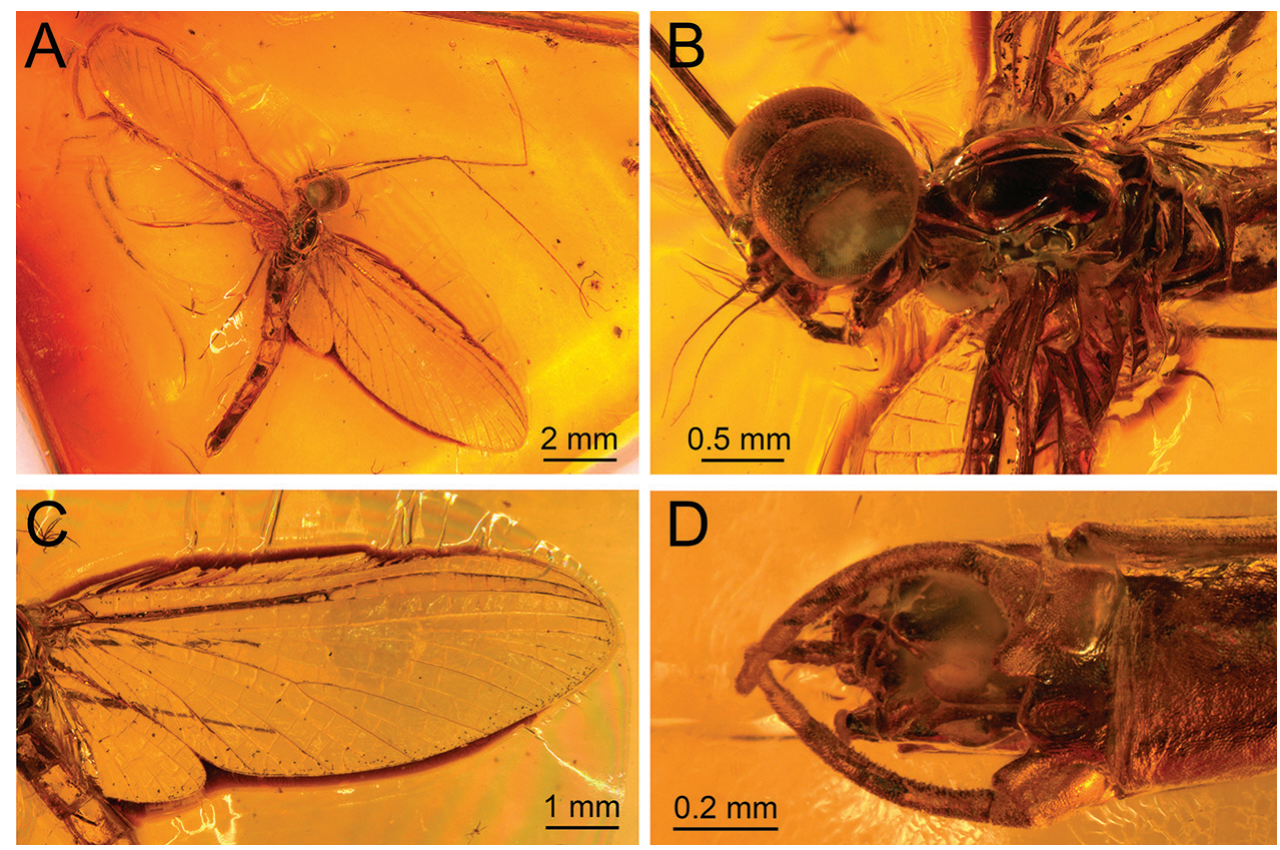

Figure 3. Siphloplecton jaegeri Demoulin, 1968, MNHN, 4655 BA, male imago (photographs) A general dorsal view (tip of abdomen twisted to ventral side) $\mathbf{B}$ head and thorax in dorsolateral view $\mathbf{C}$ right fore- and hind wing in dorsal view $\mathbf{D}$ genitalia in ventral view.

side of head and prosternum not visible, view obstructed by resin influx and cracks in stone. Foremargin and distal part of left forewing and entire left hind wing dirty brownish coloured; several dark spots on remaining part of left forewing. Such irregular pigmentation is a side effect of the specific conditions of fossilization, and must not be confused with the natural pigmentation of Siphloplecton wings (the right wings of the same specimen are colourless and translucent). Right fore- and left middle legs lost. Cerci partly damaged.

For measurements see Table 1.

Male imago in Baltic amber (Eocene), MNHN, 4655 BA (Figs 3-4).

The specimen is visible in dorsoventral and, partly, lateral aspect. Head and thorax ventrally with "Verlumung". Right fore- and hind wings fully preserved; left pair of wings partly twisted; details of cubital field not discernible. Cerci lost.

Colour yellow to yellowish-brown with darker thorax, but generally paler than all other known specimens of $S$. jaegeri. Wings hyaline, translucent, without any pigmentation.

For measurements see Table 1.

Description of specimens. General colouration from pale (yellow to yellowishbrown), to dark brown (yellowish-brown to intensively brown); details of wing colouration are described above.

Head uniformly brown. Eyes large, well developed, medially contiguous (Figs 1C, 2, 3A, 4A), slightly flattened laterally (MNB specimen); ocelli of MNHN specimen 
Table I. Measurements of fossil representatives of the Siphloplecton jaegeri species group.

\begin{tabular}{|c|c|c|c|c|c|c|c|}
\hline 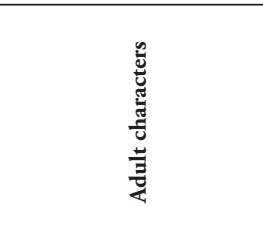 & 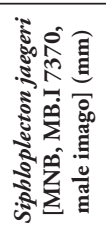 & 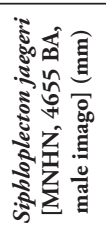 & 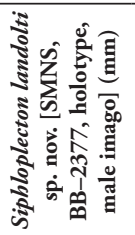 & 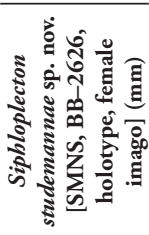 & 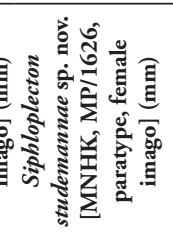 & 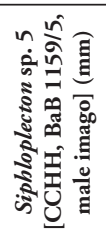 & 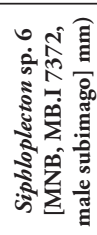 \\
\hline Length of body & 9.00 & 9.08 & 10.88 & 10.04 & 9.48 & 9.50 & 8.50 \\
\hline Length of right foreleg & - & 9.64 & - & - & - & - & 5.11 \\
\hline Length of femur & - & 1.80 & - & - & - & - & 1.77 \\
\hline Length of tibia & - & 2.00 & - & - & - & - & 1.05 \\
\hline Length of tarsus & - & 5.84 & - & - & - & - & 2.29 \\
\hline Tarsomere 1 & - & 1.40 & - & - & - & - & 0.48 \\
\hline Tarsomere 2 & - & 1.40 & - & - & - & - & 0.45 \\
\hline Tarsomere 3 & - & 1.44 & - & - & - & - & 0.48 \\
\hline Tarsomere 4 & - & 1.20 & - & - & - & - & 0.53 \\
\hline Tarsomere 5 & - & 0.40 & - & - & - & - & 0.35 \\
\hline Length of left foreleg & 8.54 & 9.40 & $3,44^{*}$ & $4.04^{*}$ & - & 13.44 & 5.04 \\
\hline Length of femur & 1.75 & 1.80 & $1.04^{*}$ & $2.02^{*}$ & - & 3.12 & 1.73 \\
\hline Length of tibia & 1.95 & 1.88 & 2.40 & 1.52 & - & 2.72 & 1.10 \\
\hline Length of tarsus & 4.84 & 5.72 & $4.64^{*}$ & $0.50^{*}$ & - & 7.60 & 2.21 \\
\hline Tarsomere 1 & 1.13 & 1.32 & 1.80 & 0.50 & - & 2.08 & 0.45 \\
\hline Tarsomere 2 & 1.13 & 1.32 & 2.00 & - & - & 1.88 & 0.45 \\
\hline Tarsomere 3 & 1.05 & 1.48 & $0.84^{*}$ & - & - & 1.64 & 0.50 \\
\hline Tarsomere 4 & 1.15 & 1.20 & - & - & - & 1.44 & 0.48 \\
\hline Tarsomere 5 & 0.38 & 0.40 & - & - & - & 0.56 & 0.33 \\
\hline Length of right middle leg & - & 3.52 & - & 4.28 & - & 7.24 & 3.86 \\
\hline Length of femur & - & 1.32 & - & 1.52 & - & 2.88 & 1.58 \\
\hline Length of tibia & - & 0.40 & - & 1.20 & - & 1.60 & 0.85 \\
\hline Length of tarsus & - & 1.80 & - & 1.56 & - & 2.76 & 1.43 \\
\hline Tarsomere 1 & - & 0.40 & - & 0.60 & - & 0.88 & 0.30 \\
\hline Tarsomere 2 & - & 0.44 & - & 0.32 & - & 0.68 & 0.40 \\
\hline Tarsomere 3 & - & 0.40 & - & 0.24 & - & 0.52 & 0.30 \\
\hline Tarsomere 4 & - & 0.40 & - & 0.22 & - & 0.32 & 0.23 \\
\hline Tarsomere 5 & - & 0.16 & - & 0.18 & - & 0.36 & 0.20 \\
\hline Length of left middle leg & $2.11^{*}$ & 3.52 & $3.48^{*}$ & 4.31 & 4.09 & 7.28 & 3.84 \\
\hline Length of femur & - & 1.32 & 1,80 & 1.52 & 1.63 & 2.92 & 1.55 \\
\hline Length of tibia & $0.63^{*}$ & 0.40 & 1.04 & 1.21 & 1.00 & 1.64 & 0.85 \\
\hline Length of tarsus & 1.48 & 1.80 & $0.64^{*}$ & 1.58 & 1.46 & 2.72 & 1.44 \\
\hline Tarsomere 1 & 0.35 & 0.40 & $0.64^{*}$ & 0.62 & 0.44 & 0.80 & 0.30 \\
\hline Tarsomere 2 & 0.50 & 0.40 & - & 0.34 & 0.45 & 0.72 & 0.40 \\
\hline Tarsomere 3 & 0.25 & 0.40 & - & 0.22 & 0.13 & 0.48 & 0.33 \\
\hline Tarsomere 4 & 0.20 & 0.40 & - & 0.20 & 0.21 & 0.36 & 0.20 \\
\hline Tarsomere 5 & 0.18 & 0.20 & - & 0.20 & 0.23 & 0.36 & 0.20 \\
\hline Length of right hind leg & 3.52 & 3.10 & - & 4.52 & $2.68^{*}$ & 6.84 & 3.54 \\
\hline Length of femur & 1.36 & 1.32 & - & 1.68 & 1.45 & 2.48 & 1.63 \\
\hline Length of tibia & 0.78 & 0.40 & - & 1.10 & 0.90 & 1.64 & 0.70 \\
\hline Length of tarsus & 1.38 & 1.38 & - & 1.74 & $0.33^{*}$ & 2.72 & 1.21 \\
\hline Tarsomere 1 & 0.35 & 0.44 & - & 0.46 & 0.33 & 0.88 & 0.30 \\
\hline Tarsomere 2 & 0.33 & 0.36 & - & 0.44 & - & 0.72 & 0.30 \\
\hline Tarsomere 3 & 0.25 & 0.22 & - & 0.38 & - & 0.48 & 0.20 \\
\hline Tarsomere 4 & 0.20 & 0.16 & - & 0.24 & - & 0.36 & 0.18 \\
\hline Tarsomere 5 & 0.25 & 0.20 & - & 0.22 & - & 0.28 & 0.23 \\
\hline Length of left hind leg & 3.43 & 3.43 & $3.40^{*}$ & 4.42 & $3.01^{*}$ & 6.84 & 3.65 \\
\hline Length of femur & 1.30 & 1.32 & 1.92 & 1.72 & 1.48 & 2.48 & 1.65 \\
\hline
\end{tabular}




\begin{tabular}{|c|c|c|c|c|c|c|c|}
\hline 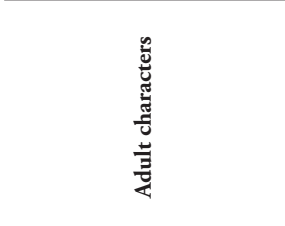 & 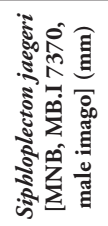 & 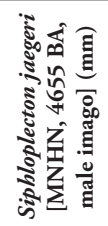 & 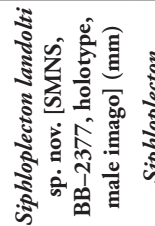 & 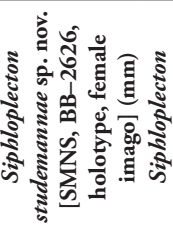 & 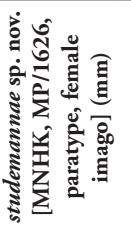 & 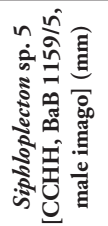 & 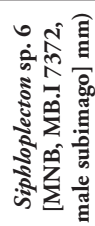 \\
\hline Length of tibia & 0.75 & 0.44 & 0.84 & 1.06 & 0.88 & 1.60 & 0.75 \\
\hline Length of tarsus & 1.38 & 1.36 & $0.64^{*}$ & 1.64 & $0.65^{*}$ & 2.76 & 1.25 \\
\hline Tarsomere 1 & 0.35 & 0.40 & $0.64^{*}$ & 0.42 & 0.30 & 0.84 & 0.30 \\
\hline Tarsomere 2 & 0.35 & 0.40 & - & 0.42 & $0.35^{*}$ & 0.76 & 0.35 \\
\hline Tarsomere 3 & 0.25 & 0.20 & - & 0.38 & - & 0.52 & 0.25 \\
\hline Tarsomere 4 & 0.18 & 0.16 & - & 0.22 & - & 0.32 & 0.15 \\
\hline Tarsomere 5 & 0.25 & 0.20 & - & 0.20 & - & 0.32 & 0.20 \\
\hline Length of right forewing & 8.13 & 8.20 & 11.60 & 8.80 & 9.95 & 9.84 & 8.75 \\
\hline Length of left forewing & 8.25 & $8.08^{*}$ & 11.80 & 8.60 & $6.88^{*}$ & 9.86 & 8.55 \\
\hline Length of right hind wing & 3.15 & 2.70 & 3.60 & - & 3.25 & 3.50 & 2.75 \\
\hline Length of left hind wing & 3.20 & - & $3.25^{*}$ & 2.92 & 3.30 & 3.52 & 2.80 \\
\hline Hind/forewings length ratio & 0.39 & 0.39 & 0.31 & 0.34 & 0.33 & 0.36 & 0.32 \\
\hline Length of right cercus & $4.25^{*}$ & - & $2.84^{*}$ & $2.24^{*}$ & 3.03 & - & $4.25^{*}$ \\
\hline Length of left cercus & $4.20^{*}$ & - & $3.16^{*}$ & $2.32^{*}$ & 4.50 & 8.80 & $4.00^{*}$ \\
\hline
\end{tabular}

* - preserved part; “-” - not preserved.

with slightly paler apical part and darker basally; antennae light brown, longer than head (Fig. 3A); ocelli and antennae of MNB specimen not visible due to resin influxes (Fig. 1A-C).

Thorax brown with dirty maculation dorsally (MNB specimen), yellowish-brown with markedly darker sterna (MNHN specimen); mesonotal suture stretched backwards medially; lateroparapsidal suture elongated, without surrounding pigmentation; furcasternal protuberances of mesothorax fused.

Wings hyaline. Pterostigma with at least 6 anastomosed veins. Cubital field of right forewing with well-developed intercalary vein (iCu1) close to $\mathrm{CuA}$ and basally directly connected to it, followed by one pair of intercalaries (iCu2, iCu3) basally connected to each other and connected to $\mathrm{CuA}$ (in MNHN specimen also to $\mathrm{CuP}$ ) by a short crossvein (Figs 1D, 2, 4A). Hind wings with triads RS, MA and MP (Fig. 4A); preserved part of hind wings $0.39 \times$ forewing length (MNB specimen). Hind wings of MNHN specimen with triads RS, MA and MP, poorly visible distally; preserved part of hind wings $0.35 \times$ forewing length. Costal process small.

Legs brownish; tibiae and tarsi darker than femora; structure and proportions of leg segments similar to those of holotype of $S$. jaegeri; outer margin of foretibia with pointed setae; measurements of leg segments in Table 1.

Abdominal segments well preserved, paler than thorax. Shape of styliger and penis lobes (Figs 1E, 3D, 4B) similar to those of $S$. jaegeri holotype (Demoulin 1968: 252, figs 18a, c, Staniczek and Godunko 2012: 74, fig. 11c). Styliger plate angulate, deeply incised with three prominent projections; medial projection markedly broad; basal segment of forceps basally (a) markedly narrower than adjoining apical part of styliger plate $(\mathrm{b})(\mathrm{a} / \mathrm{b}=0.57)$; forceps 4 -segmented; segment 2 longest, segment 4 approximately 2.47 to 2.65 times as long as wide; length ratio of segment 3 to segment 4 

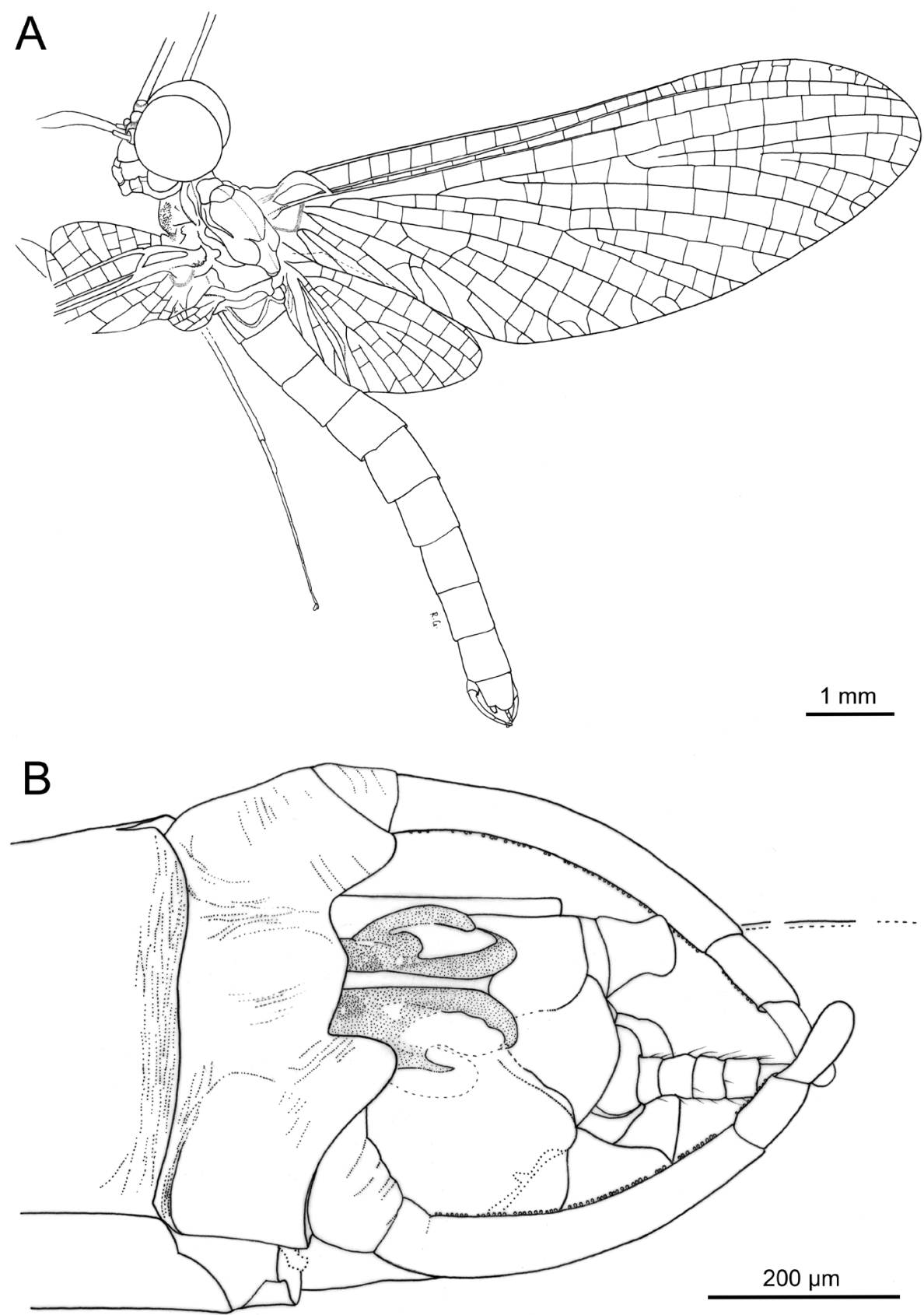

Figure 4. Siphloplecton jaegeri Demoulin, 1968, MNHN, 4655 BA, male imago (line drawings) A general dorsal view $\mathbf{B}$ genitalia in ventral view.

approximately 0.9:1. Penis lobes elongated, medially incised, triangular, with relatively inconspicuous incision between lateral and medial penis sclerites. Surface details of penis lobes not visible. 
Paracercus vestigial, 5-segmented.

Comments. Some minor differences regarding the proportions of the fore/hind wings and forceps segments between the holotype of $S$. jaegeri and the specimens described above are present. However, we attribute these specimens to $S$. jaegeri due to the presence of $1+2$ intercalaries in the cubital field, pointed setae along outer margin of foretibia, and the shape of styliger plate and penis lobes.

\section{Siphloplecton landolti sp. nov.}

http://zoobank.org/F5338779-9D55-48B5-9542-7357704A8A64

Figures 5-7; Table 1

Material examined. Holotype. Male imago in Baltic amber (Eocene), SMNS BB2377. Well preserved specimen in clear amber, well visible in dorsoventral aspect. Each of both forewings bent upwards approximately at half length (left forewing partly twisted); left hind wing twisted; genitalia visible in ventral and, partly, lateral view.

For measurements see Table 1.

Description. Colouration pale, dorsal side slightly darker than ventral side. Brownish diffuse maculation on thorax and abdomen preserved. Ocelli well preserved. Eyes large, medially contiguous; brownish maculation on eye surface partly preserved; antennae longer than head (Figs 5A-C, E, 6A-B).

Thorax with traces of brownish pigmentation on dorsal and ventral sides; "Verlumung" mainly on lateral sides near wing bases. Lateroparapsidal suture elongate, typical for Siphloplecton; no conspecific pigmentation around lateroparapsidal suture; mesonotal suture medially bulged (Fig. 6A); furcasternal protuberances of mesothorax contiguous (Fig. 6B); lateral aspect of thorax hardly visible.

Wings translucent, hyaline, not pigmented, venation well visible; pterostigma translucent, without pigmentation, with simple veins. Cubital field of forewing well visible on right wing only (twisted on left wing): one distinct pair of intercalary veins (iCu2 and $\mathrm{iCu} 3$ ) situated close to $\mathrm{CuP}$ and connected with $\mathrm{CuP}$ and $\mathrm{CuA}$; one long intercalary vein $(\mathrm{iCu} 1)$ connected with $\mathrm{CuA}$ and also with $\mathrm{iCu} 2$ by crossveins; additional short intercalaries present, ending at hind margin of wing (one of them between iCu1 and $\mathrm{iCu} 2$, basally joining both veins) (Fig. 5C). Hind wings with triads RS, MA and MP, $0.31 \times$ forewing length; costal process bluntly pointed (Fig. 5D).

Legs damaged; both right fore- and hind legs lost; tarsus of left foreleg only partly preserved (for details see Table 1). Tibia of left foreleg paler than femur and tarsus. Left foretibia with strong, sharply pointed setae along outer margin. Tibia of left middle and hind legs black; preserved part of first tarsomere of left middle leg black. Tibia of middle and hind legs with trace of tibiopatellar suture; first tarsomere of middle and hind legs fused with tibia. Tarsal claws lost (Fig. 5A-B).

Abdominal segments completely preserved, sterna visibly paler than terga; genitalia dark.

Styliger plate angulate, mediocaudally deeply incised; these incisions with pronounced, broad, triangular projections; medial projection not large, blunt apically 

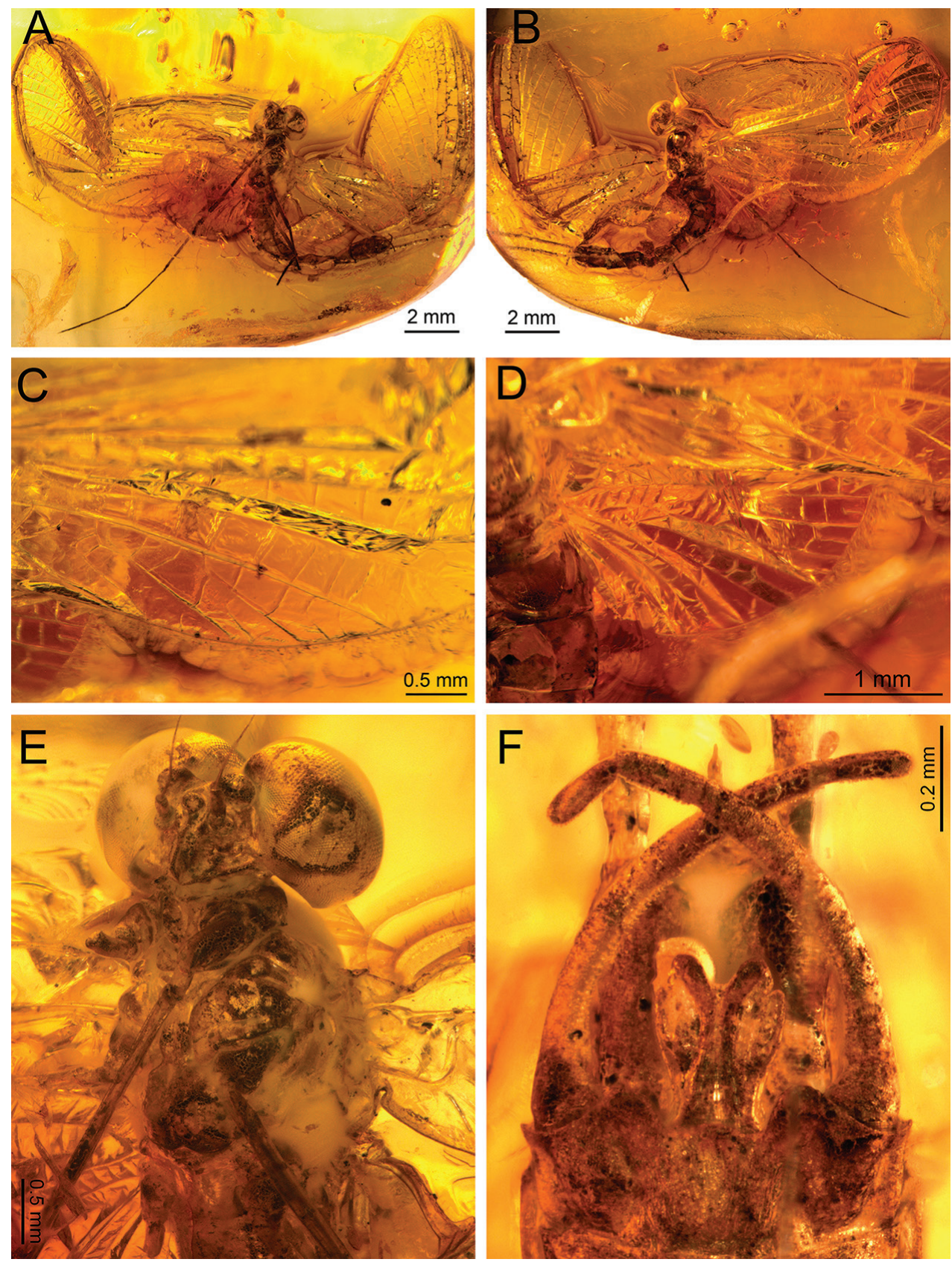

Figure 5. Siphloplecton landolti sp. nov., SMNS, BB-2377, holotype, male imago (photographs) A general dorsal view $\mathbf{B}$ general ventral view $\mathbf{C}$ cubital field of right forewing $\mathbf{D}$ right hind wing in dorsal view $\mathbf{E}$ head and thorax in ventral view $\mathbf{F}$ genitalia in ventral view.

(Figs 5F, 7). Basal segment of forceps basally relatively wide; forceps 4-segmented, segment 4 approximately 3.30 times longer than wide; length ratio of segment 3 to segment 4 approximately 1:1. Penis lobes distinctly elongated, well separated from each 
A
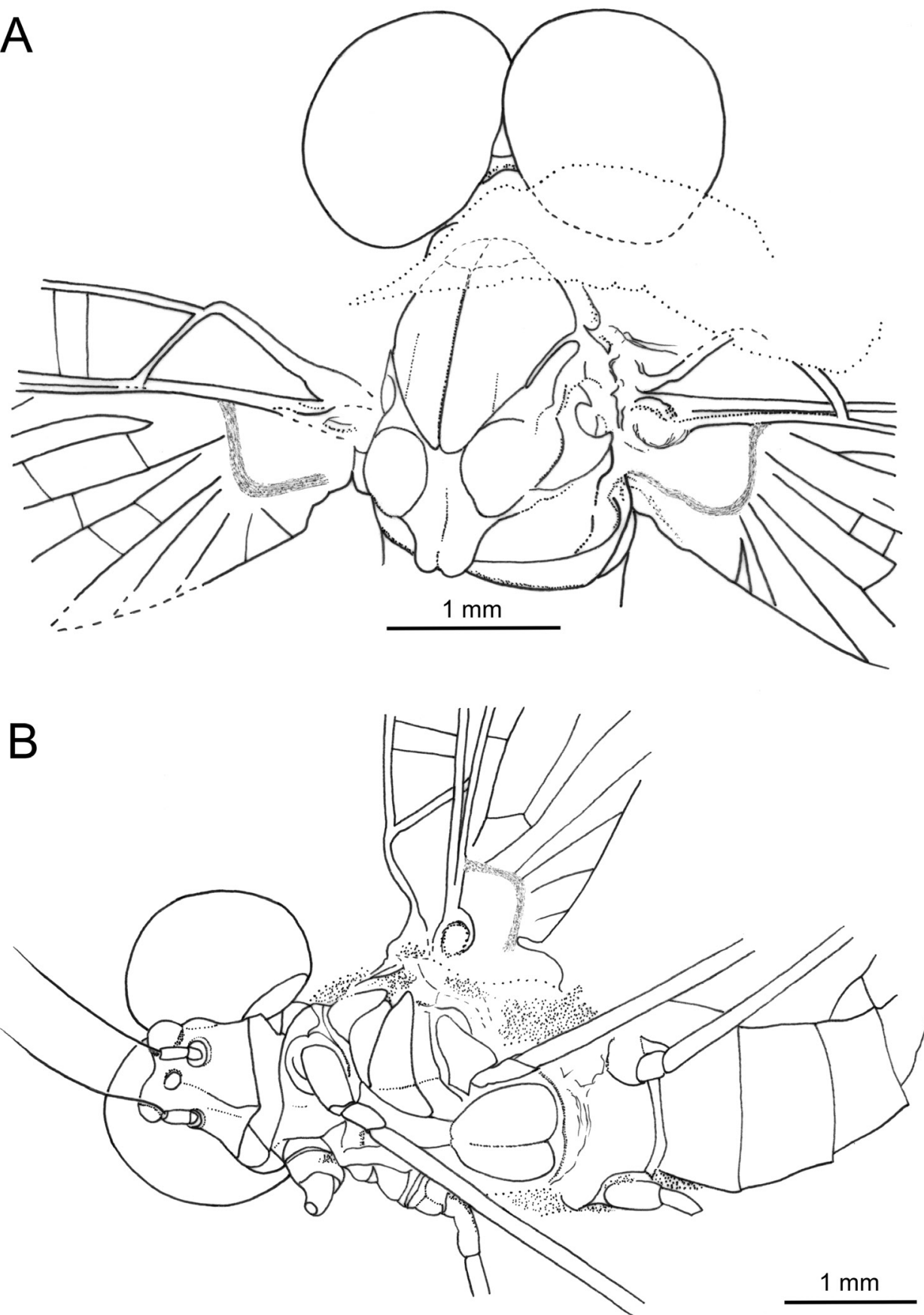

Figure 6. Siphloplecton landolti sp. nov., SMNS, BB-2377, holotype, male imago (line drawings) A head and thorax in dorsal view $\mathbf{B}$ head and thorax in ventral view. 


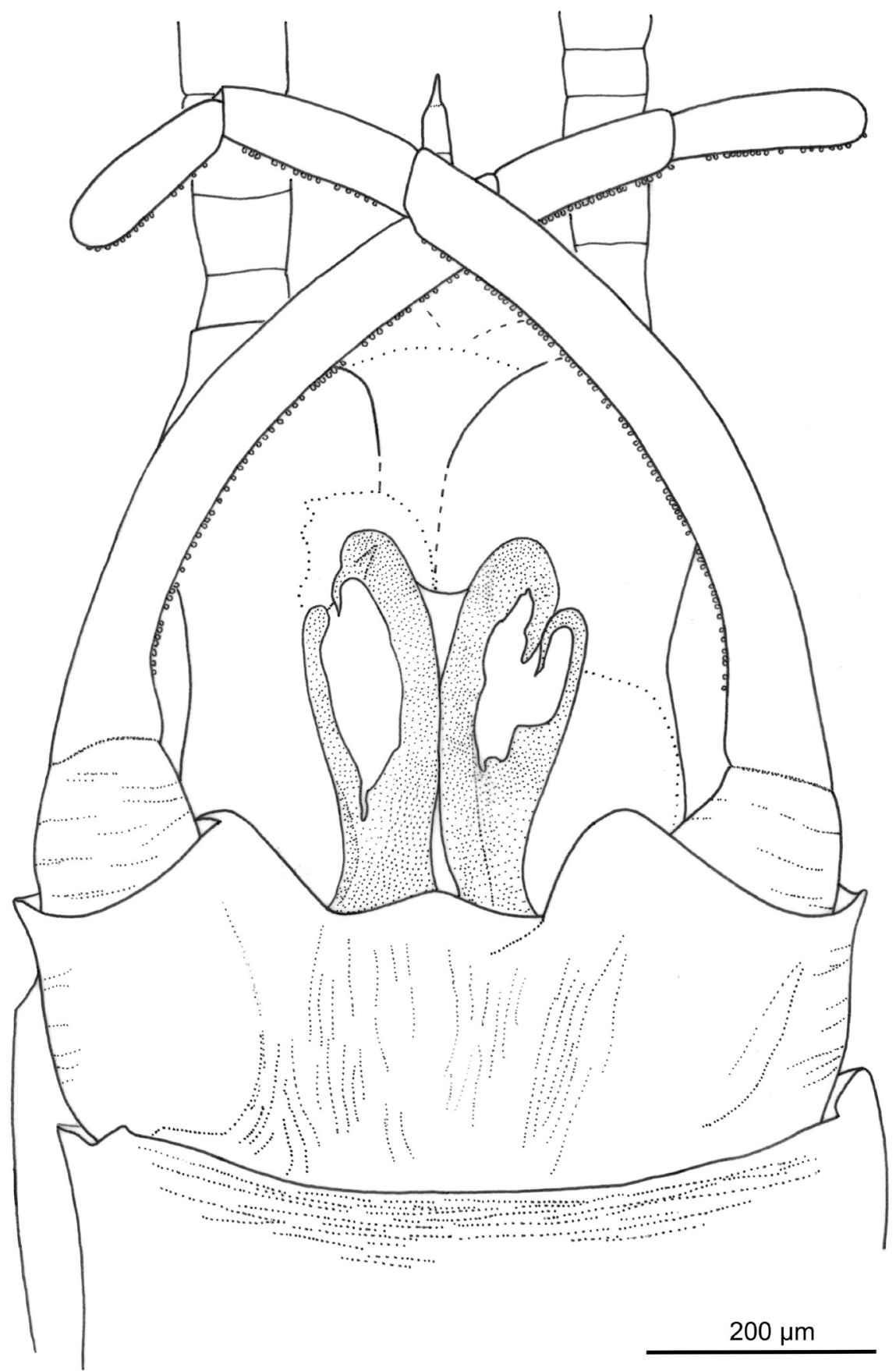

Figure 7. Siphloplecton landolti sp. nov., SMNS, BB-2377, holotype, male imago (line drawing): genitalia in ventral view. 
other apically, ellipsoidal; medial sclerite rounded apically; lateral and medial sclerite markedly separated on outer side with inconspicuous incision between sclerites; features of ventral surface of penis lobes not visible (Figs 5F, 7).

Paracercus vestigial; cerci partly lost.

Comments. The new species can be placed within the jaegeri species group based on the characteristic shape of the penis lobes, the arrangement of cubital intercalaries of the forewing and the sharply pointed setae along the outer margin of the foretibia. Siphloplecton landolti sp. nov. can be separated from the closely related S. jaegeri by (1) shape of styliger with relatively small and apically rounded medial projection; (2) relatively wide base of basal forceps segment compared to adjoining apical part of styliger plate; (3) proportions of last forceps segments; (4) ellipsoidal shape of penis lobes with medial sclerite rounded at tip.

The body measurements of $S$. landolti sp. nov. are comparable to other representatives of the $S$. jaegeri species group, but the ratio of hind/forewing length is lower in comparison with $S$. jaegeri itself.

Etymology. Following our tradition of naming new fossil species of Siphloplecton after Swiss ephemeropterists, this species is named after Peter Landolt, Lausanne, to honour his contributions to the knowledge of Swiss mayflies.

\section{Siphloplecton studemannae sp. nov.}

http://zoobank.org/2D1C8631-DAFF-4B84-B10D-7D7FAB3E5334

Figures 8-11; Table 1

Material examined. Holotype. Female imago in Baltic amber (Eocene), SMNS BB2626. Well preserved specimen in clear amber, well visible in dorsoventral aspect. Right foreleg lost; hind wings (especially left wing) twisted. Head and thorax covered by "Verlumung". Additionally, piece of amber with numerous cracks, thus details of thoracic terga invisible, and thorax only partly visible from ventral side. For measurements see Table 1 .

Paratype. Female imago in Baltic amber (Eocene), MNHK, MP/1626. Partly damaged specimen, visible in ventral aspect. View on body hampered by resin influxes, numerous cracks, and considerable "Verlumung", so thoracic sutures are hardly visible. Head lost. Pronotum damaged, its structure invisible. Distal part of mesonotum, metanotum and abdominal segments I-IV dorsally covered by plant tissue. Right forewing twisted along its length; left forewing lacks its basal part and distal end. Right foreleg, right middle leg, left middle tarsus, and both hind legs lost. Cerci only partly preserved. For measurements see Table 1.

Description of holotype. General colour of body pale, yellow to yellowish-brown. Ventral side of body slightly darker than dorsal side. Ocelli well preserved. Eyes medially separated, but approximated (Fig. 8A). Distance between eyes $0.22 \times$ of head width. Antennae complete, slightly longer than head, pale. 

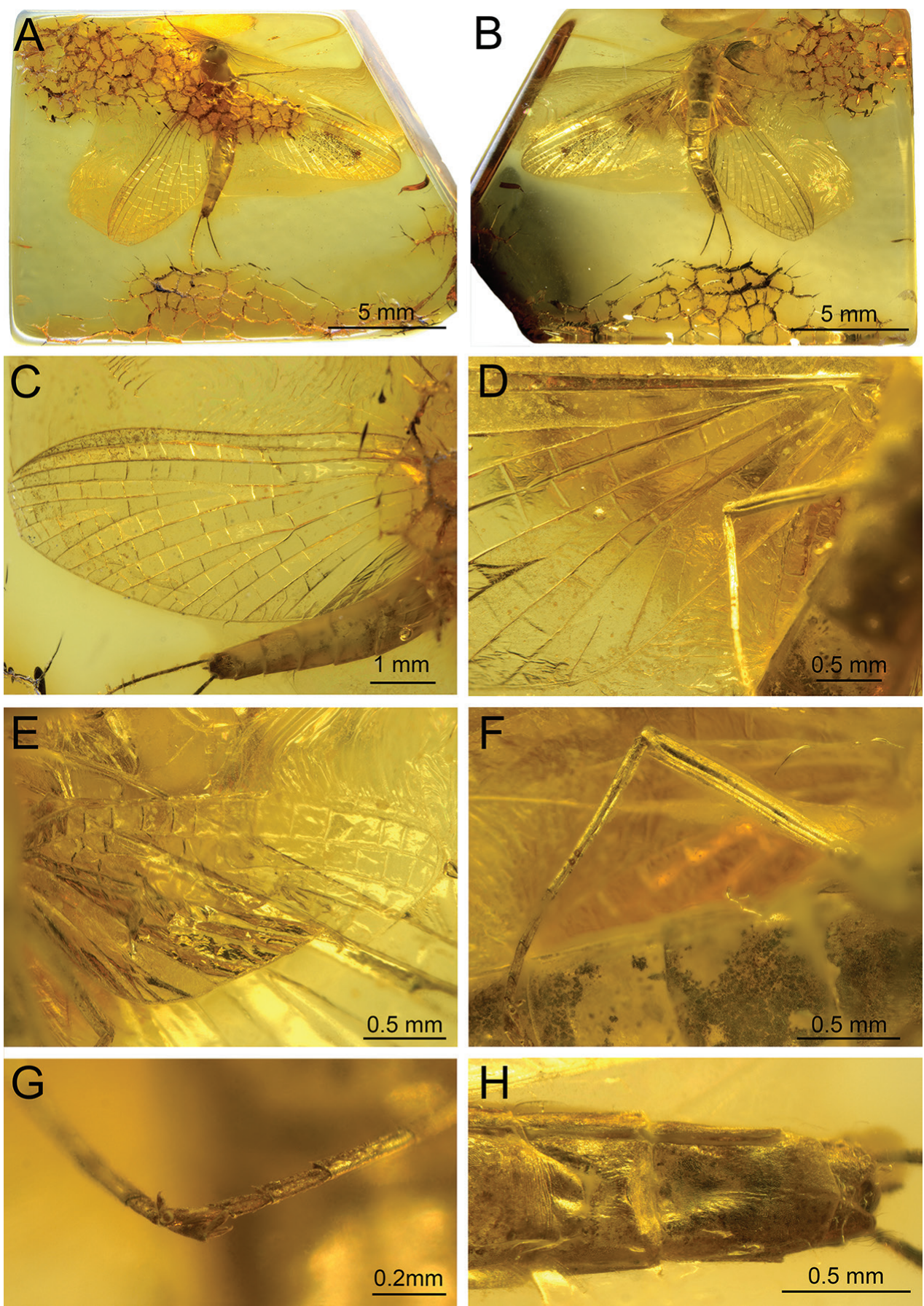

Figure 8. Siphloplecton studemannae sp. nov., SMNS, BB-2626, holotype, female imago (photographs) A general dorsal view $\mathbf{B}$ general ventral view $\mathbf{C}$ left forewing in dorsal view $\mathbf{D}$ wing base and cubital field of right forewing in ventral view $\mathbf{E}$ left hind wing in ventral view $\mathbf{F}$ right hind leg in medial view $\mathbf{G}$ claws of hind legs $\mathbf{H}$ abdominal segments VII-X in ventral view. 


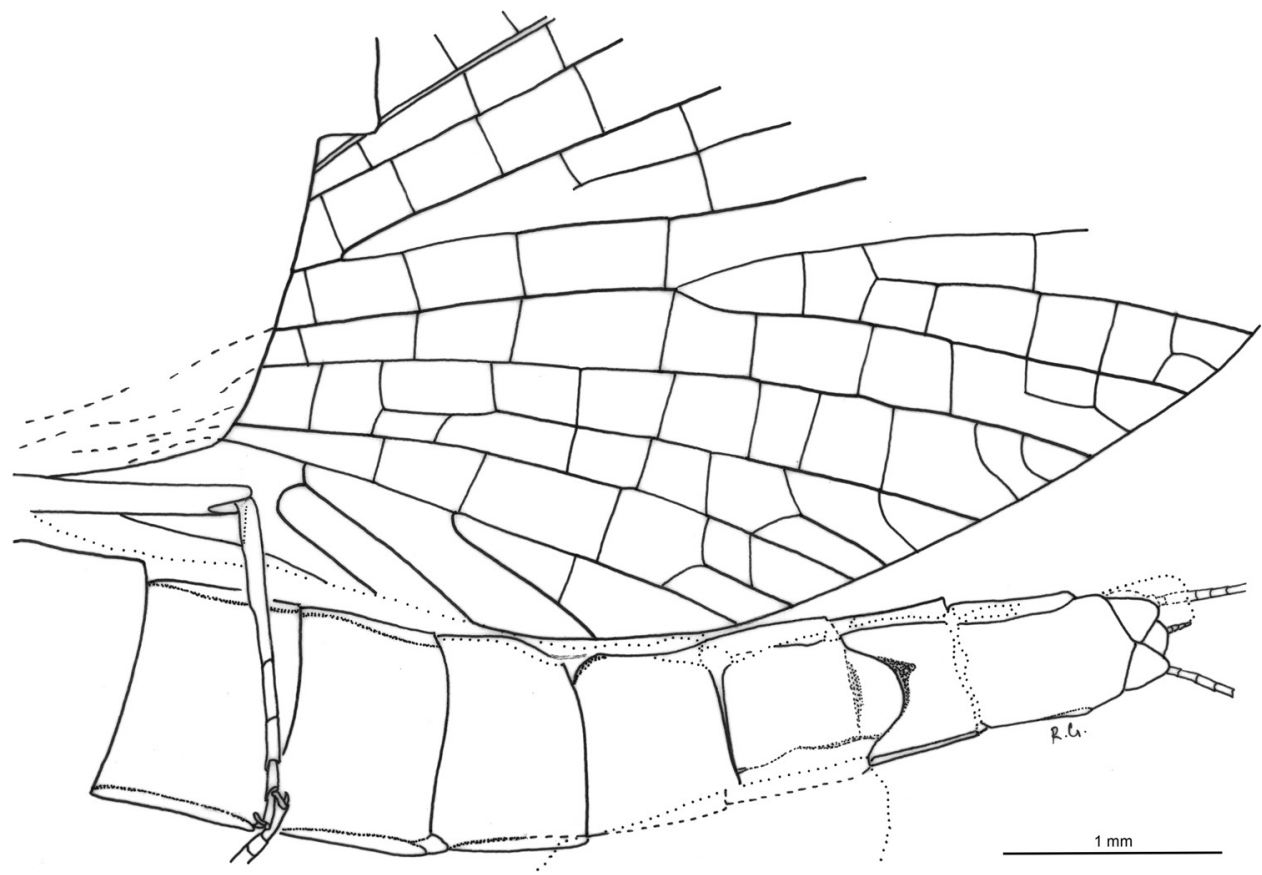

Figure 9. Siphloplecton studemannae sp. nov., SMNS, BB-2626, holotype, female imago (line drawing): abdomen and part of left forewing in ventral view.

Thorax ventrally yellowish coloured by "Verlumung", mainly in posterior part. Furcasternal protuberances of mesothorax contiguous (Fig. 8B); lateral aspect of thorax not visible.

Wings translucent, hyaline, not pigmented. Wing venation well visible only from ventral side; basal part of wings covered by numerous cracks from dorsal side. Cubital field of both forewings with one pair of intercalary veins (iCu2, iCu3) towards $\mathrm{CuP}$ and one additional vein (iCu1) near CuA (Figs 8C-D, 9). Right hind wing hardly visible, twisted; left hind wing completely preserved with three pairs of triads, $0.34 \times$ of right forewing length. Costal process bluntly pointed apically and small (Fig. 8E).

Legs relatively well preserved, except forelegs (right is lost; left incomplete). Measurements of leg segments in Table 1. Tibiae of middle and hind legs each with trace of tibiopatellar suture; first tarsomere of middle and hind legs fused with tibia (Fig. 8F). Tarsi with 5 tarsomeres; tarsal claws dissimilar: one hooked and one blunt (Fig. 8G).

Abdominal segments completely preserved, pale; terga VIII-X slightly darker than remaining terga. Abdominal sterna slightly covered by "Verlumung". Subgenital plate relatively broad, $2.00 \times$ as wide as long, convex and rounded apically. Subanal plate not elongated, narrow, with pointed tip (Figs $8 \mathrm{H}, 9)$. Paracercus poorly visible, vestigial, with at least 4 visible segments; cerci dark, partly preserved.

Description of paratype. Body colouration light, yellowish-brown to brown. Irregular brown, dirty brown to black maculation over body, especially on forewings and legs (Fig. 10A). 

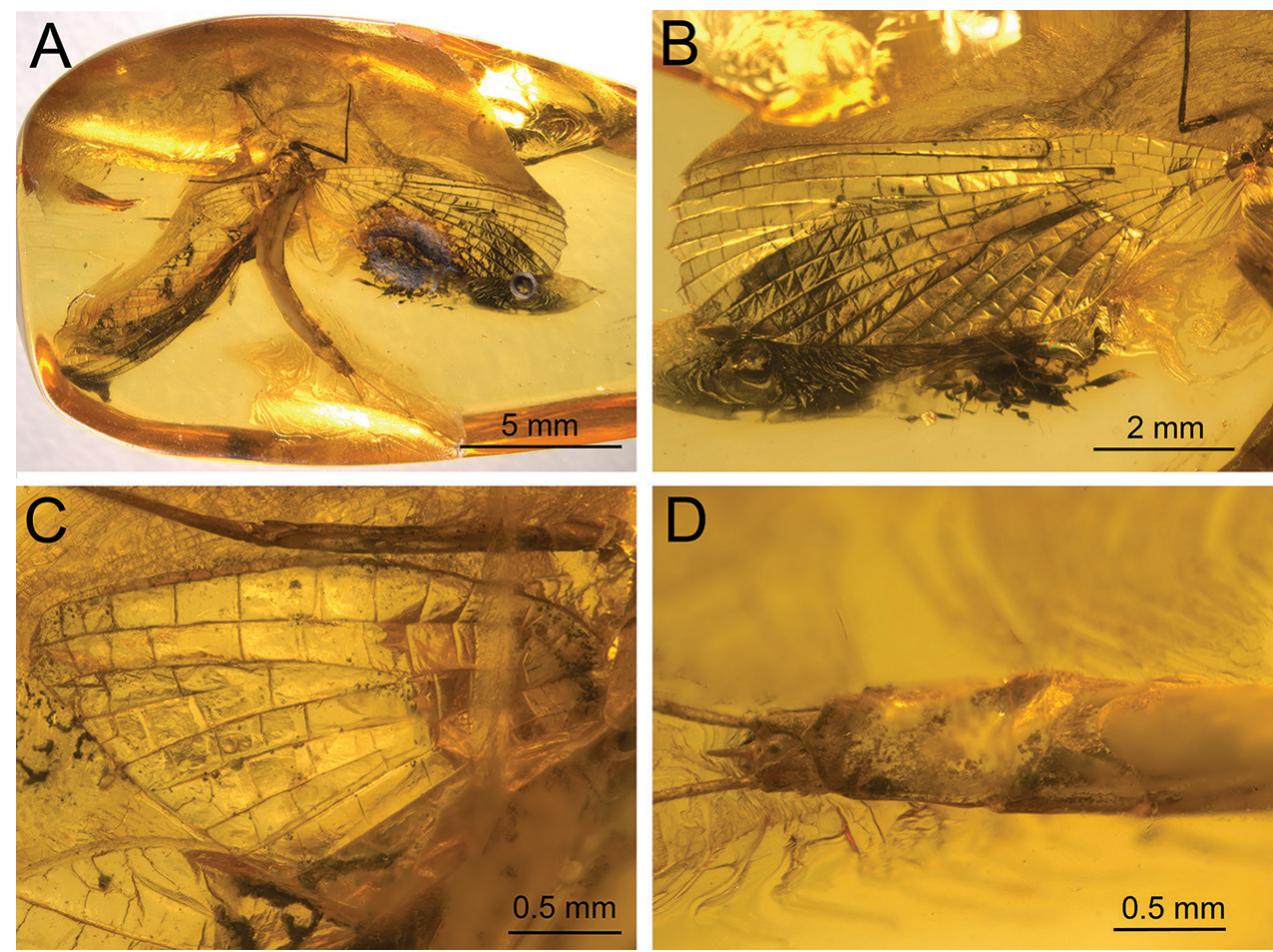

Figure 10. Siphloplecton studemannae sp. nov., MNHK, MP/1626, paratype, female imago (photographs) A general ventral view $\mathbf{B}$ left forewing in dorsal view $\mathbf{C}$ right hind wing in ventral view $\mathbf{D}$ abdominal segments VII-X in ventral view.

Details of mesonotum hardly visible; mesonotal suture typical for Siphloplecton, original lateroparapsidal suture colouration invisible due to resin influx. Furcasternal protuberances contiguous, distinctly brown; other parts of mesosternum paler.

Pterostigma with anastomosed crossveins. Cubital field of right forewing well preserved; iCu1 basally connected to $\mathrm{CuA}$ and iCu2 by crossveins, 2 additional $\mathrm{CuA}-$ $\mathrm{iCu} 1$ crossveins present. Pair of intercalaries iCu2 and iCu3 basally connected to each other; further crossveins connect to $\mathrm{CuA}$ and $\mathrm{CuP}$ (Figs 10B, 11A). Hind wings relatively long, approximately $0.40 \times$ of length of preserved right forewing; costal processes hardly visible. Hind wings with triads RS, MA and MP; costal process (visible only on right hind wing) small and blunt (Fig. 10C).

Left foreleg intensely brown to blackish distally; middle legs paler, yellow to yellowish-brown. Preserved foreclaw dissimilar (one claw hooked, one claw blunt).

Most of abdominal segments ventrally covered with "Verlumung". Preserved sterna paler than terga. Subgenital plate not elongate, approximately $1.80 \times$ wide as long, widely rounded apically. Subanal plate not elongate, pointed at tip (Figs 10D, 11B). Paracercus 5-segmented.

Comments. We allocate Siphloplecton studemannae sp. nov. within the S. jaegeri species group based on the presence of three distinctive intercalaries (grouped in one pair and 


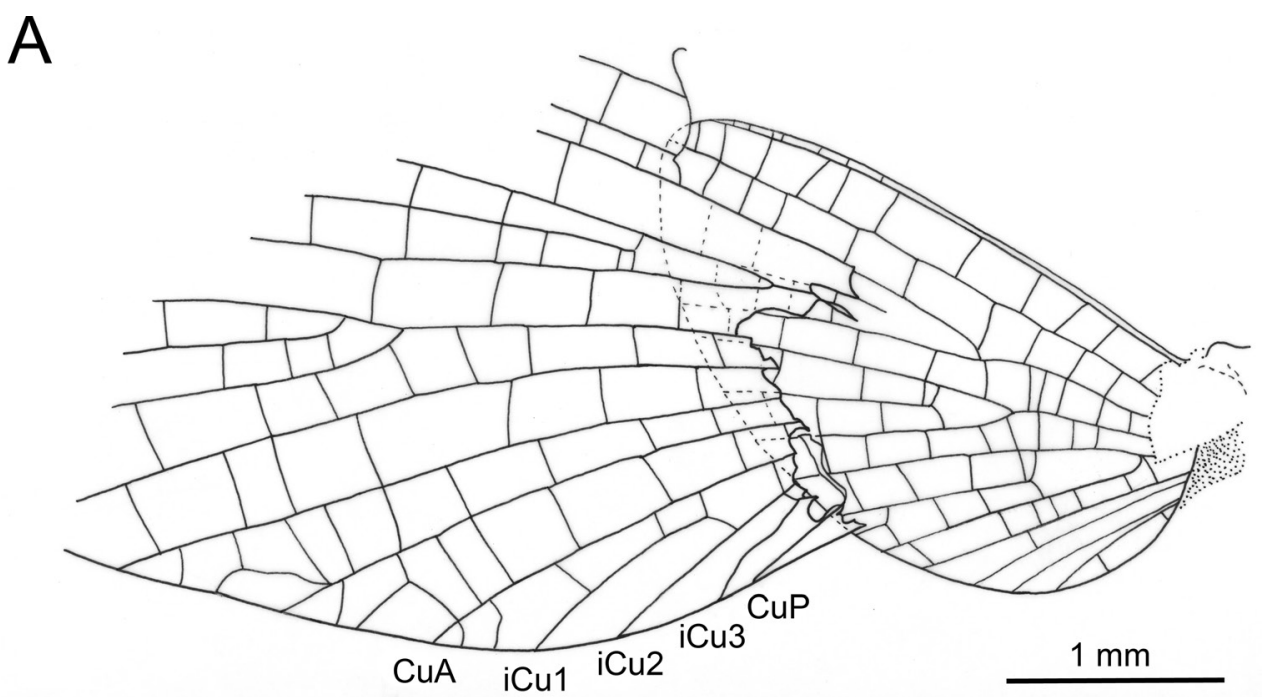

B

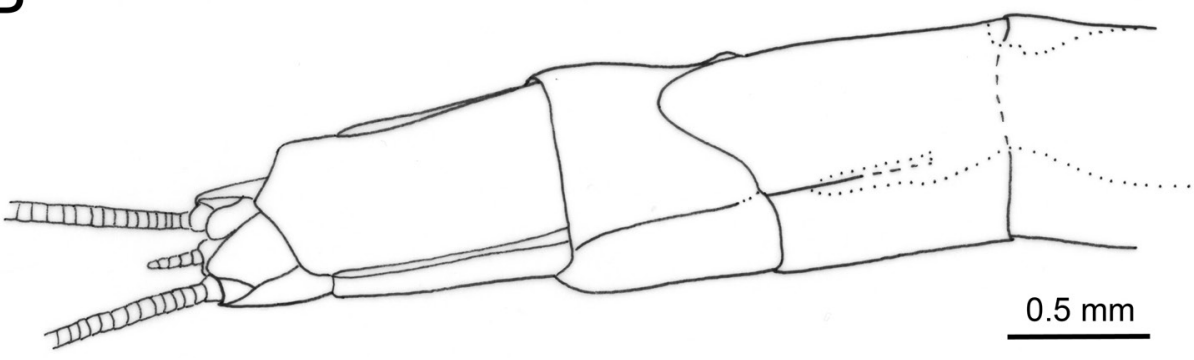

Figure I I. Siphloplecton studemannae sp. nov., MNHK, MP/1626, paratype, female imago (line drawings) A fragments of left fore- and hind wings, dorsal view $\mathbf{B}$ abdominal segments VII-X in ventrolateral view.

one additional intercalary vein) in the cubital field of both forewings. The same arrangement of intercalary veins was described and figured for the holotype of $S$. jaegeri by Staniczek and Godunko (2012: 73, 74, fig. 10b). Other diagnostic characters of this species group, namely the presence of sharply pointed setae at the outer margin of the foretibia, cannot be observed in the type specimens of $S$. studemannae sp. nov. So it cannot be excluded that this character is present in the females of this fossil species, similarly to the different occurrence of this character in the two sexes of extant species (Berner 1978).

The new species can be characterized by the presence of the following characters: (1) eyes separated, but close-set; (2) cubital field of forewings with one pair of intercalaries and one intercalary vein connected with $\mathrm{CuA}$; (3) subgenital plate relatively broad with width/length ratio $1.80-2.00$. This combination of characters definitely separates the described females of $S$. studemannae sp. nov. from all other previously known Recent and fossil taxa. 
Siphloplecton studemannae sp. nov. is currently the only species of the genus Siphloplecton described from female specimens that can also be attributed to a certain species group. This is only possible due to the unique arrangement of cubital intercalaries, which is characteristic for the $S$. jaegeri species group. The previously described $S$. barabani and $S$. hageni, also only known from female specimens, do not provide any clear distinguishing characters that would allow their placement in one of the other fossil species groups defined for Siphloplecton, which can only be grouped based on similarities in the male genitalia.

Etymology. Following our tradition of naming new fossil species of Siphloplecton after Swiss ephemeropterists, this species is named after Denise Studemann, Lausanne, to honour her contributions to the knowledge of Swiss mayflies.

\section{Siphloplecton spp. (jaegeri species group)}

\section{Siphloplecton sp. 5}

Figures 12-13; Table 1

Material examined. Male imago in Baltic amber (Eocene), CCHH, BaB Nr. 1159/5. A generally completely preserved specimen, well visible in dorsoventral aspect in translucent amber (Fig. 12A-B). Some resin influxes around specimen. Right foreleg and right cercus lost. Dorsal side of body only with several very small spots of "Verlumung". Ventral side of head, thorax and, partly, abdominal sterna intensively covered with "Verlumung". For this reason, some aspects of mesosternum and the shape of the genitalia are poorly visible. One female nonbiting midge (Diptera: Chironomidae) is embedded in the same stone.

Relatively pale specimen, yellowish to brown. Wings with artificial, irregular dark spots; distal portions of forewings and right hind wing with distinct concentration of such spots (Fig. 12E). Legs uniformly coloured. For measurements see Table 1.

Description. Head light brown. Eyes large, slightly flattened, pale, dirty yellowish. Several brownish spots on eye surface. Ocelli and antennae of same colouration as head, completely preserved; antennae slightly longer than head (Fig. 12C, E).

Thorax with traces of brownish pigmentation on dorsal and ventral sides, brown. Pronotum well preserved. Arrangement of thoracic sutures on dorsal and ventral sides of mesothorax typical for Siphloplecton (Figs 12C-D, 13). Most of head and thorax ventrally covered with "Verlumung". Lateral aspect of thorax hardly visible.

Wings basally translucent, hyaline, with well visible longitudinal and transversal venation. Pterostigmatic area hyaline, opaque, with several anastomosed veins. Cubital field of forewings with well visible pair of intercalary veins connected with $\mathrm{CuA}$, and one additional, well developed vein also directed toward CuA (Figs 12E-G, 13). Hind wings with triads RS, MA and MP, $0.36 \times$ forewing length; costal process bluntly pointed and small (Figs 12E, 13). 

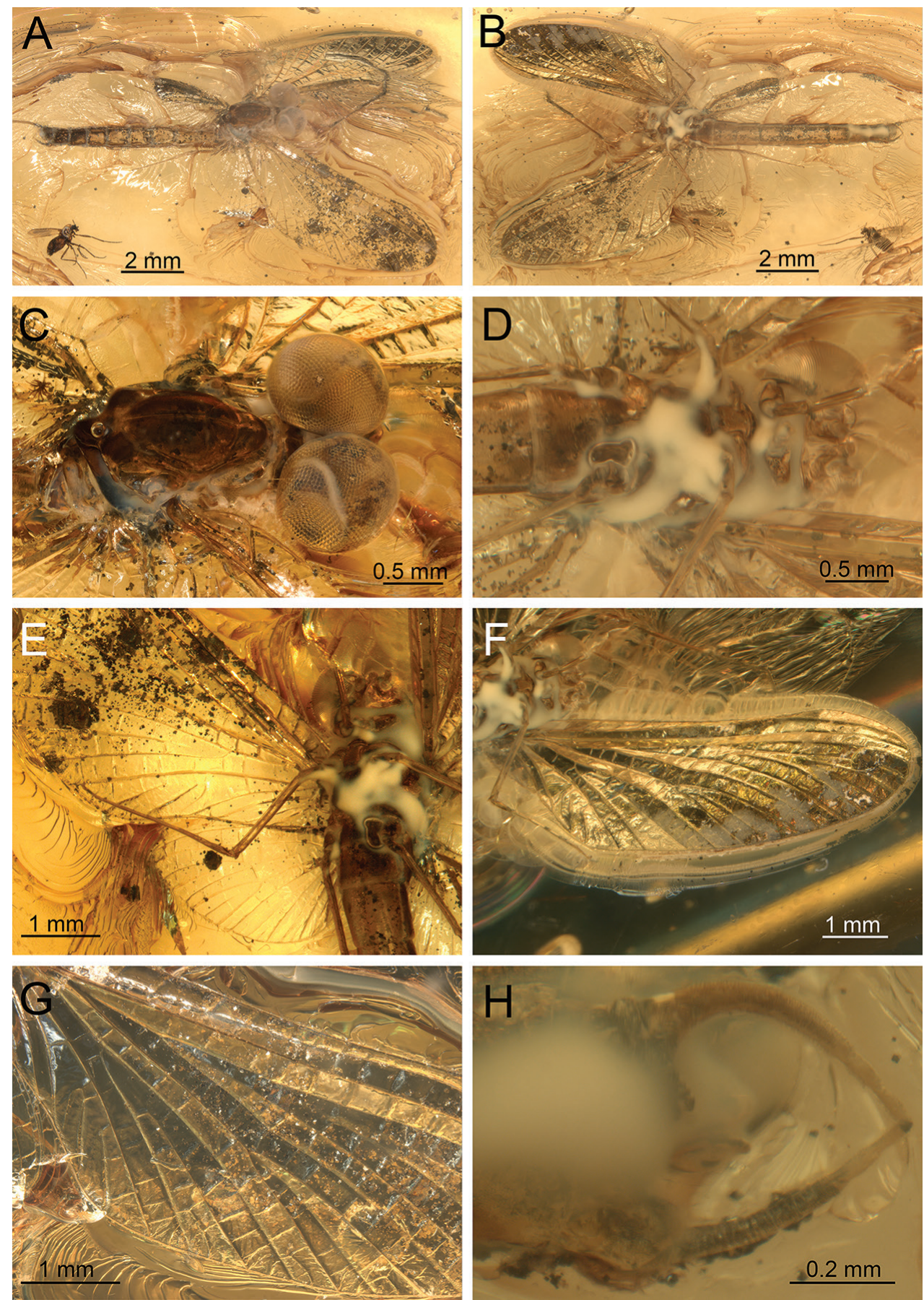

Figure 12. Siphloplecton sp. 5, CCHH, BaB 1159/5, male imago (photographs) A general dorsal view $\mathbf{B}$ general ventral view $\mathbf{C}$ head and thorax in dorsal view $\mathbf{D}$ head and thorax in ventral view $\mathbf{E}$ base of right forewing and hind wing in ventral view $\mathbf{F}$ left forewing in ventral view $\mathbf{G}$ cubital field of left forewing in ventral view $\mathbf{H}$ genitalia in ventral view. 


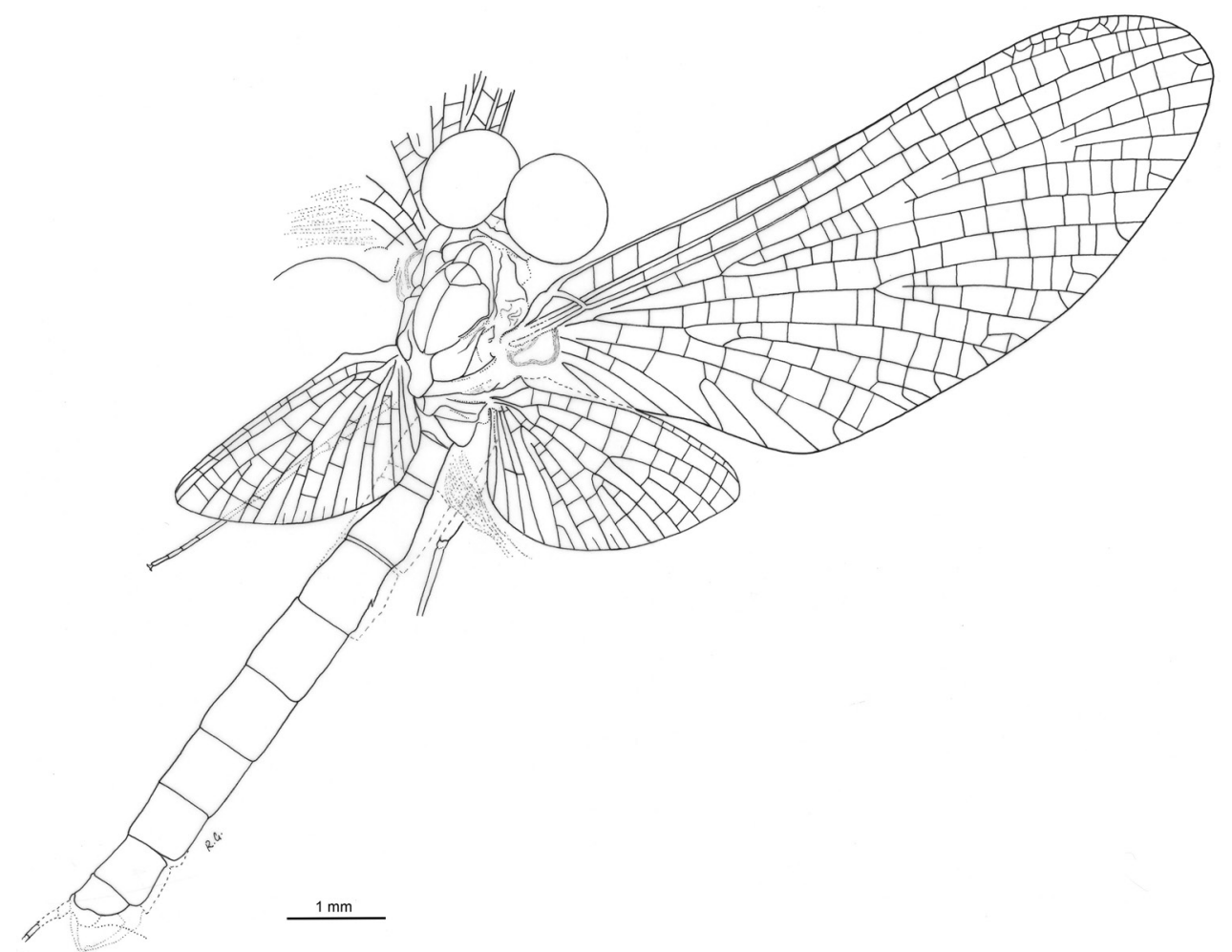

Figure 13. Siphloplecton sp. 5, CCHH, BaB 1159/5, male imago (line drawing): general dorsal view of body, right forewing, left and right hind wings.

Legs yellowish to light brown. Several pointed spines at outer margin of foretibia. Characteristics of legs similar to those of other representatives of Siphloplecton. Measurements of leg segments in Table 1.

Abdominal segments completely preserved; abdominal terga slightly paler than sterna.

Styliger plate only partly visible, most of styliger base covered with "Verlumung". Thus, shape of styliger projections not clearly visible (Fig. 12H). Basal segment of forceps basally not widened, distinctly narrower than adjoining apical part of styliger plate (character well visible only in right clasper); forceps 4-segmented, segment 4 approximately 3.20 times longer than wide; length ratio of segment 3 to segment 4 approximately 1:1 (Fig. 12H).

Penis lobes covered with "Verlumung" (especially left lobe); penis lobes elongated, relatively narrow and separated from each other apically; medial sclerite rounded apically; lateral and medial sclerites probably separated on outer side (poorly visible) (Fig. 12H).

Paracercus vestigial, at least 3-segmented; left cercus slightly damaged; right cercus lost. 
Comments. This species is closely related to S. landolti sp. nov. due to the similar proportions of the forceps segments and shape of the penis lobes, especially the apical portion of the medial sclerite, and the presence of $2+1$ intercalary veins in the cubital field of the forewings. This last character also confirms the inclusion of Siphloplecton sp. 5 within the $S$. jaegeri species group. At the same time, we could not confirm its conspecificy with Siphloplecton landolti sp. nov. or other species, since the details of the male genitalia are poorly visible.

\section{Siphloplecton sp. 6}

Figure 14; Table 1

Material examined. Male subimago in Baltic amber (Eocene), MNB, MB.I 7372, specimen originally labeled as: "6. Pseudoneuroptera III Ephemeridae"; "Museum für Naturkunde Berlin”; "Paläontologisches Museum”; "Slg.: Künow Inv. Nr.: Nr. 268294 nur noch 9 Stück vorgefunden”; "Ephemeriden“; "Siphloplecton cf. jaegeri subim. male Nr.: 272".

Completely preserved specimen, well visible in lateral aspect. Details of head hardly visible due to resin influxes and small cracks in stone. Left forewing arcuated at half length; left hind wing twisted. Terga IX-X and, partly, genitalia covered by "Verlumung". For measurements see Table 1.

Description. General colouration of body brown to dark brown. Head brown with paler antennae; eyes large, medially contiguous, uniformly brown coloured.

Thorax intensely brown; details of terga hardly visible; mesonotal suture typical for Siphloplecton; lateroparapsidal suture not visible. Thorax ventrally hardly visible, but furcasternal protuberances of mesothorax contiguous.

Wings opaque. Forewings with several irregular dark spots (probably an artefact of fossilisation). Pterostigmatic area with 7-8 anastomosed veins. In cubital field of forewing one pair of intercalaries close to $\mathrm{CuP}$ (connected with $\mathrm{CuP}$ and $\mathrm{CuA}$ ); one additional intercalary vein close to $\mathrm{CuA}$. Hind wings with triads RS, MA and MP, $0.32 \times$ forewing length; costal process bluntly pointed (Fig. 14).

Legs typical for the genus Siphloplecton.

Abdominal segments completely preserved; terga darker than sterna.

Shape of styliger plate poorly visible in ventral view, but generally close to the one of $S$. landolti (deeply incised mediocaudally, angulate, with relatively small medial projection). Shape of penis lobes hardly visible because of "Verlumung". Visible part of penis lobes with apical sclerites rounded at tip.

Cerci partly damaged; paracercus vestigial.

Comments. Due to the general shape of the styliger and penis lobes, and proportions of the fore/hind wings, this specimen belongs with high probability to $S$. landolti sp. nov. Some of the observed differences might be related to differences between subimago and imago, or may be due to the bad preservation of the genitalia. However, in order to avoid any taxonomic confusion, we refrain from attributing Siphloplecton sp. 6 to a certain species within Siphloplecton. 


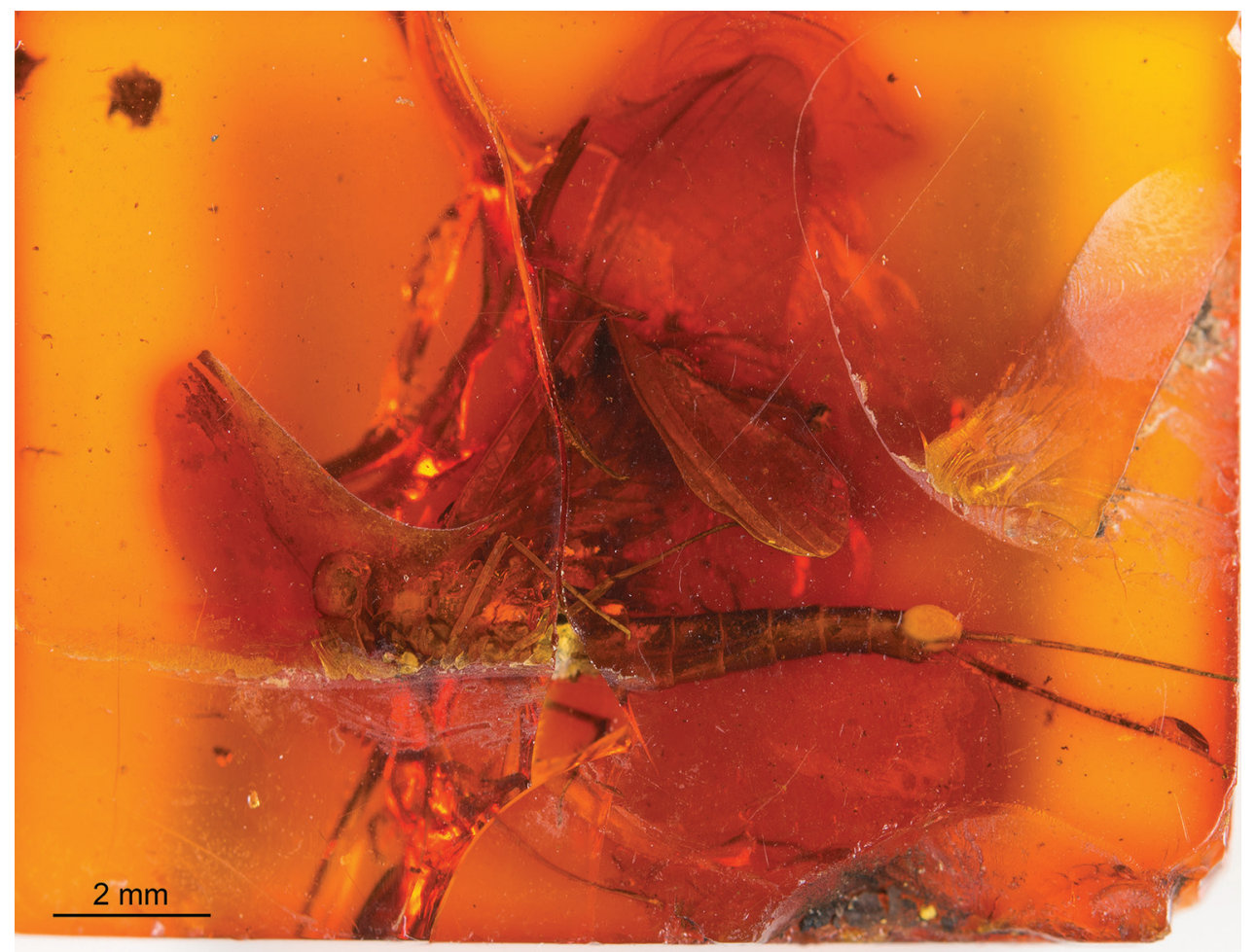

Figure I4. Siphloplecton sp. 6, MNB, MB.I 7372, male subimago (photograph): general lateral view, left side.

\section{Discussion}

The first classification of extant representatives of the genus Siphloplecton into species groups was undertaken by Berner (1978) in his work dedicated to the taxonomy of Metretopodidae. That grouping was based on wing pigmentation, the shape of the setae along the outer margin of the foretibia, and penis shape (Berner 1978: 96; Staniczek and Godunko 2012: 59-61, figs 1-2). Staniczek and Godunko (2012), for the first time, added fossil Siphloplecton species from Eocene Baltic amber to Recent species groups. In this contribution, $S$. picteti and $S$. demoulini were attributed to the $S$. basale species group established by Berner (1978). At the same time, the remaining investigated taxa, S. barabani and S. hageni, were neither attributed to the basale species group nor to the interlineatum species group. This was due to these species having only been described from female imagines, and no traces of wing pigmentation were preserved. Siphloplecton jaegeri was also excluded from previously known species groups for peculiarities in the genitalia and for the presence of pointed setae along the outer margin of the foretibia (Staniczek and Godunko 2012). In fact, these characters pointed to a relatively isolated position of $S$. jaegeri within both fossil and recent species of Siphloplecton.

Based on the investigation of further male specimens, Staniczek and Godunko (2016) established another two Siphloplecton species groups for four fossil species: 
S. picteti and S. sartorii were attributed to the S. picteti species group, and S. demoulini and $S$. gattolliati to the $S$. demoulini species group. At the same time, due to the poor preservation of the re-discovered lectotype of $S$. macrops, Staniczek and Godunko (2016) concluded that it is neither possible to define any distinguishing characters for this species nor to attribute it to any of the species groups proposed earlier. They also refrained from placing female specimens in the $S$. sartorii or demoulini species groups.

Representatives of the genus Siphloplecton are relatively abundant components of the mayfly fauna from Eocene Baltic amber. Judging from the museum and private collections investigated by us, this genus is not less abundant than Paraleptophlebia Lestage, 1917 (Leptophlebiidae), which is another commonly found mayfly genus in Baltic amber. Taxonomically, the genus Siphloplecton, with ten fossil and nine contemporary Nearctic species, is rather diverse.

\section{Key to males of Siphloplecton from Eocene Baltic amber}

1 Four long intercalary veins grouped into two pairs in the cubital field of the forewings between $\mathrm{CuA}$ and $\mathrm{CuP}$ (Staniczek and Godunko 2012: 66, 76, figs 4C, 12C; Staniczek and Godunko 2016: 14, 19, 23, figs 7A, 11A, 13A) ................ 2

- Three long intercalary veins grouped into one pair and one separate intercalary vein in the cubital field of the forewings between $\mathrm{CuA}$ and $\mathrm{CuP}$ (Figs 1D, 2, 4A, 8D, 9, 10B, 11A, 12E, G, 13) [S. jaegeri species group] ................................

2 Outer margin of foretibia with two or more stout, pointed setae; penis relatively short, its tip barely reaching distal margin of basal forceps segment $[S$. picteti species group] 3

- Outer margin of foretibia without stout, pointed setae; penis elongated, its tip significantly projecting beyond styliger plate, reaching one fourth of forceps segment $2[S$. demoulini species group] ................................................................ 4

3 Basal segment of forceps nearly square; segment 4 of forceps moderately elongated (segment length/width ratio 2.58-2.72); forceps segments 3 and 4 of about same length; penis lobes contiguous almost along entire length, separated only by a shallow, broad, U-shaped cleavage apically; lateral sclerites of penis lobes relatively slender, only slightly expanding laterally (Staniczek and Godunko 2012: 64, fig. 3b; Staniczek and Godunko 2016: 12, 14-16, figs 6D, 7B, 8E, 9B)

\section{S. picteti}

- Basal segment of forceps slim and elongated; segment 4 of forceps clearly elongated (segment length/width ratio 3.38); forceps segment 3 slightly longer than segment 4; penis lobes well separated apically by a wide, V-shaped cleft; lateral sclerites of penis lobes distinctly broad and prominent laterally (Staniczek and Godunko 2016: 18, 19, figs 10H, 11B) S. sartorii

4 Median projection of styliger plate slightly prominent, triangular (Staniczek and Godunko 2012: 76, 77, figs 12d, 13c).... S. demoulini

- Median projection of styliger plate absent (Staniczek and Godunko 2016: 22, 23, figs 12F, 13B) 
5 Median projection of styliger plate well protruded, broad, triangular-shaped; basal segment of forceps basally markedly narrower than adjoining apical part of styliger plate; penis lobes distinctly elongated, nearly triangular-shaped apically (Figs 1E, 3D, 4B; Demoulin 1968: 253, fig. 18b; Staniczek and Godunko 2012: 74, fig. 11c)

S. jaegeri

- Median projection of styliger plate relatively small, rounded apically; basal segment of forceps basally relatively wide in comparison to adjoining apical part of styliger plate; penis lobes distinctly elongated, smoothly rounded apically (Figs 5F, 7)

S. landolti

\section{Acknowledgements}

Our thanks go to Christel and Hans Werner Hoffeins (Hamburg), André Nel (MNHN, Paris), and Wiesław Krzemiński (MNHK, Kraków) for access to their collections. We are also thankful to Milan Pallmann (SMNS) for the colour photographs. This study was financially supported by DFG grant STA 1098/1-1 to AHS and conducted with institutional support RVO 60077344 (IE, BC CAS) to RJG. The stay of RJG at SMNS was supported by a Georg Forster Research Fellowship for Experienced Researchers by the Alexander von Humboldt Foundation. Investigations of type specimens at MNB by RJG were supported by DAAD scholarships (2004, 2008), investigations of type specimens at MNHN by RJG were supported by SYNTHESYS (http://www.synthesys. info/), which was financed by the European Community Research Infrastructure Action.

\section{References}

Berner L (1978) A review of the family Metretopodidae. Transactions of the American Entomological Society 104: 91-137.

Demoulin G (1968) Deuxième contribution à la connaissance des Ephéméroptère de l'amber oligocène de la Baltique. Deutsche Entomologische Zeitschrift 15(1-3): 233-276. https:// doi.org/10.1002/mmnd.4810150110

Demoulin G (1970) Troisième contribution à la connaissance des Éphéméroptères de l'ambre oligocène de la Baltique. Bulletin de l'Institut Royal des Sciences Naturelles de Belgique 46(2): 1-11.

Kluge NJ (2004) The Phylogenetic System of Ephemeroptera. Dortrecht, Kluwer, 442 pp. https://doi.org/10.1007/978-94-007-0872-3

Pictet-Baraban FJ, Hagen H (1856) Die im Bernstein befindlichen Neuropteren der Vorwelt. In: Berendt GC (Ed.) Die im Bernstein Befindlichen Organischen Reste der Vorwelt. Zweiter Band, II. Abtheilung. Nicolaische Buchhandlung, Berlin, 41-126.

Staniczek AH, Godunko RJ (2012) Revision of fossil Metretopodidae (Insecta: Ephemeroptera) in Baltic amber. - Part 1: Type specimens of hitherto described fossil species of Siphloplecton Clemens, 1915 and Metretopus Eaton, 1901, with description of four new fossil species of Siphloplecton. Palaeodiversity 5: 57-87. 
Staniczek AH, Godunko RJ (2015) Revision of fossil Metretopodidae (Insecta: Ephemeroptera) in Baltic amber. - Part 2: Description of a new species of Metretopus Eaton, 1901. Historical Biology 27(7): 861-867. https://doi.org/10.1080/08912963.2014.910203

Staniczek AH, Godunko RJ. (2016) Revision of fossil Metretopodidae (Insecta: Ephemeroptera) in Baltic amber. - Part 3: Description of two new species of Siphloplecton Clemens, 1915, with notes on the re-discovered lectotype of Siphloplecton macrops (Pictet-Baraban \& Hagen, 1856). Zootaxa 4103(1): 1-24. https://doi.org/10.11646/zootaxa.4103.1.1 